\title{
Encapsulation and Germination of Synthetic Seeds of Chrysanthemum
}

\author{
Pangesti Nugrahani*, Ida Retno Moeljani, Irda Lydiana \\ Department of Agrotechnology \\ Universitas Pembangunan Nasional "Veteran" Jawa Timur \\ Surabaya, Indonesia \\ *Email: pangesti_n@upnjatim.ac.id
}

\begin{abstract}
Chrysanthemum is one of the most important Indonesia flowers, that which has always been developed in various plant breeding studies, including the development of synthetic seed encapsulation methods. Encapsulation is a technology on enclosed any meristematic plant tissue in a protective and nutritive matrix under in vitro or in vivo environmental conditions, also after transport and/or storage. The study were aimed at developing a method of encapsulating shoot tip and nodal segments of Chrysanthemum that can be used for plant propagation and as explants for short-term storage. Shoot tip and nodal segments of Chrysanthemum were used as explants for synthetic seed. The Murashige \& Skoog (MS) basal medium was prepared with $30 \mathrm{~g}$ sucrose and $4 \%$ of sodium alginate added with growth regulator (IBA) and Coconut Water $(\mathrm{CW})$. The explants droplets, each containing one shoot tip, were then maintained in $2 \% \mathrm{CaCl} 2$ solution for polymerization. The seeds that have been formed were rinsed with distilled water sterile 3 times and dried at room temperature. The synthetic seeds were germinated on MS basal medium, without any plant growth regulators. Encapsulated seeds had a higher germination percentage in MS salt solution as the gel matrix supplemented with $150 \mathrm{ml} / \mathrm{L}$ coconut water. The viability of synthetic seeds was decrease on 4 weeks storage period, compared to the 1,2 and 3 week's storage period.
\end{abstract}

Keywords-Encapsulation, Germination, Synthetic Seed, Chrysanthemum

\section{INTRODUCTION}

Chrysanthemum is one of the most important Indonesia flowers. Many varieties of Chrysanthemum were introduced by Indonesia research centre of ornamental plants. It used as a cut flower, pot plant, and in the any kind of flower decoration.

Synthetic seed technology is an effort to make seeds with artificial materials as a substitute for capsules on the actual seeds. This synthetic seed technology is developed using somatic embryos and other micropropagules. The results of this technology have been successfully applied in the field, greenhouses and on other commercial planting techniques [1]. Synthetic seed technology is also carried out in the framework of micropropagation and conservasion of rare and endangered germplas of economically plants. However, the widespread application of synthetic seed technology in agriculture is still not optimal. This is due to the lack of high-quality micropropagules production [2]. The technology also provides its importance in ex vitro conservation as the encapsulation protects the plant sample from the unfavorable effects of toxic cryoprotectants and post-storage damages [3].

In a decade later, encapsulation of nodal segments with $\mathrm{Ca}$ alginate to develop artificial seeds has been investigated in many plant species [1, 4-7]. It also developing in many horticulture plants research published such as Begonia [8], strawberry [9], Chrysanthemum [10], Oxalis [11] etc. The research on encapsulation technology is currently mainly carried out with a focus on the development of its technology, constrains and commercial prospects for the future [12].

Artificial seed works in encapsulation technology is part of the progress of plant biotechnology that is feasible to be developed in large-scale artificial seed production [13]. Development of synthetic seed encapsulation technology has been carried out in various countries around the world. In Indonesia, synthetic seed encapsulation technology is still limited to laboratory scale research. Synthetic seeds developed in Indonesia in several types of plants, such as Potato [14] Pineapple [15], Sugarcane [16], tea [17], Moringa oleifera [18].

It was stated by [19] that encapsulation technology at the moment is still being developed and presents some open questions that have to be solved. Encapsulation and synthetic seed are useful for the effective channel for diffusion of new plant genotypes, direct sowing of synthetic seed in field, greenhouse or growth chamber; plants material storage; biodiversity conservation; exchange of in vitro plant material between laboratories and nurseries in different countries [19]. Recent advance in the production of artificial seeds reveal that beside somatic embryos, encapsulation of cells and tissues developed in vitro is becoming popular [20].
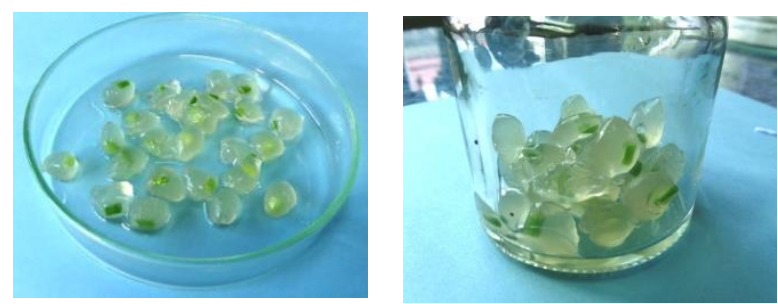

Fig 1: Prepared encapsulated of Chrysanthemum: (a) Explants were submerged in sodium alginate solution (b) Each explants released into a container of $\mathrm{CaCl} 2$. $\mathrm{H} 2 \mathrm{O}$ and keep to the storage bottle

The study were aimed at developing a method of encapsulating shoot tip and nodal segments of Chrysanthemum 
that can be used for plant propagation and as explants for shortterm storage.

\section{MATERIALS AND METHOD}

\section{A. Preparing synthetic seed}

Shoot tips and single nodes of Chrysanthemum explant were used as propagule for synthetic seed. Those 3- mm long of propagule was obtain from 4 months old of in vitro Chrysanthemum plantlets. One liter of MS medium was prepared with $30 \mathrm{~g}$ sucrose and $25 \mathrm{~g}$ of sodium alginate added with growth regulator (IBA) and Coconut water (CW).

Encapsulation was accomplished by mixing the propagule into the sodium alginate solutions and dropping these individually into the calcium chloride $(\mathrm{CaCl} 2)$ solution. The $2 \%$ $\mathrm{CaCl} 2$ was prepared by adding $20 \mathrm{~g}$ calcium chloride into one litre distilled water.

Each droplets containing one propagule is then store in the $\mathrm{CaCl} 2$ solution and gently soaked for about 20 minutes. Encapsulated seed are the washed in sterile distilled water to remove calcium chloride residues. The synthetis seed that have been formed are rinsed again with sterile distilled water for 3 times and dried at room temperature.

\section{B. Treatments on germination}

The effect of BAP and coconut water in 9 treatments on germination of synthetic seed was assessed. The treatments are BAP 0, 1, and 2 ppm and coconut water 0, 100, and $150 \mathrm{ml} / \mathrm{L}$ on full strength MS basal medium, with repetition three times.

Synthetic seeds that have been formed, then grown in vitro on MS medium for 4 weeks in a $20{ }^{\circ} \mathrm{C}$ incubating room.

The number of dead, stagnant seed and germinating synthetic seeds were counted for each treatment after 1, 2, 3, and 4 weeks. The percentage of seeds in the observation, also calculated based on the total of synthetic seeds tested. The day's emergence of meristematic shoots also recorded after 1 , 2, 3, and 4 week's storage period.

\section{RESULT\& DISCUSSION}

\section{A. Encapsulation}

The results of this study indicate that synthetic seeds of chrysanthemum plants can be well made by methods that described above. Likewise [20] which states that synthetic seed can be a good tool for plant propagation and store propagules for a reasonable period of time. The steps involved in the scheme used for encapsulation of Chrysanthemums shoot tip and nodes are mentioned above. Fig. 1 showed the prepared synthetic seed ready to take in storage and germinated.

Germination and seed storage to find out the seed germination based on the storage period, the observations were carried out every week. The seeds were germinated on MS solid media, without any plant growth regulators. Germination was observed for 2 weeks after planting. The following were germination percentage data for various storage periods. Fig. 3 showed the emergence of meristematic shoots.
Even it was reported that the high concentration or the long exposure of the embryos to the calcium chloride results in more absorption and penetration of $\mathrm{CaCl} 2$ in the embryo, which can lead to growth inhibition [21]. But based on Fig.2, it can be seen that the percentage of germination of synthetic chrysanthemum seeds showed that there were not significantly different at each storage period. At 1 week storage period showed the lowest germination percentage obtained in BAP $2 \mathrm{ppm}+$ Coconut Water $0 \mathrm{ml} / 1$, which was $65.0 \%$ and the highest germination percentage was obtained in BAP 0 ppm + Coconut Water 150 $\mathrm{ml} / 1$, that was $76.7 \%$. Synthetic seeds with 2 weeks storage period, the Control obtained the lowest germination percentage $(50.5 \%)$ and BAP 0 ppm + Coconut Water $150 \mathrm{ml} / 1$ treatment was the highest germination percentage $(75.5 \%)$. In the 3 weeks storage period, the lowest germination percentage was obtained by BAP $2 \mathrm{ppm}+$ Coconut Water $0 \mathrm{ml} / 1$, which was $42.5 \%$, while the best germination percentage was obtained by BAP 0 $\mathrm{ppm}+$ Coconut Water $150 \mathrm{ml} / \mathrm{l}$, that was $60.5 \%$.

Synthetic seeds on 4 weeks storage period experienced a decrease in germination percentage when compared to the 1,2 and 3 weeks. The Control showed the lowest germination percentage $(24.5 \%)$, while the best germination percentage was obtained by BAP 0 ppm + Coconut Water $150 \mathrm{ml} / 1$ (52.5\%).

However, based on statistical analysis, all data showed that there were no significant differences on the germination percentage, based on storage period.

\section{TABLE 1. CONVERTION OF ENCAPSULATED SEED INTO PLANTLET}

\begin{tabular}{|l|c|c|c|c|}
\hline \multirow{2}{*}{ Treatments } & \multicolumn{4}{c|}{ Emergence of shoots (days) } \\
\cline { 2 - 5 } & 1 week & 2 weeks & 3 weeks & 4 weeks \\
\hline Control & $6.60 \mathrm{~d}$ & 6.80 & 6.90 & 7.20 \\
\hline BAP $0 \mathrm{ppm}+\mathrm{CW} 100 \mathrm{ml} / \mathrm{L}$ & $6.40 \mathrm{~b}$ & 6.70 & 6.80 & 7.10 \\
\hline BAP $0 \mathrm{ppm}+\mathrm{CW} 150 \mathrm{ml} / \mathrm{L}$ & $6.30 \mathrm{a}$ & 6.60 & 6.70 & 7.20 \\
\hline BAP $1 \mathrm{ppm}+\mathrm{CW} 0 \mathrm{ml} / \mathrm{L}$ & $6.40 \mathrm{~b}$ & 6.70 & 6.90 & 7.20 \\
\hline BAP $1 \mathrm{ppm}+\mathrm{CW} 100 \mathrm{ml} / \mathrm{L}$ & $6.50 \mathrm{c}$ & 6.70 & 6.80 & 7.10 \\
\hline BAP $1 \mathrm{ppm}+\mathrm{CW} 150 \mathrm{ml} / \mathrm{L}$ & $6.40 \mathrm{~b}$ & 6.60 & 6.80 & 7.10 \\
\hline BAP 2 ppm + CW 0 ml/L & $6.60 \mathrm{~d}$ & 6.70 & 6.70 & 7.10 \\
\hline BAP 2 ppm + CW $100 \mathrm{ml} / \mathrm{L}$ & $6.60 \mathrm{~d}$ & 6.70 & 6.80 & 7.10 \\
\hline BAP 2 ppm + CW $150 \mathrm{ml} / \mathrm{L}$ & $6.50 \mathrm{c}$ & 6.70 & 6.80 & 7.20 \\
\hline LSD at $5 \%$ & 0.02 & NS & NS & NS \\
\hline
\end{tabular}

*Mean with the same letter in the columns are not significantly different at $P=0.05$. 


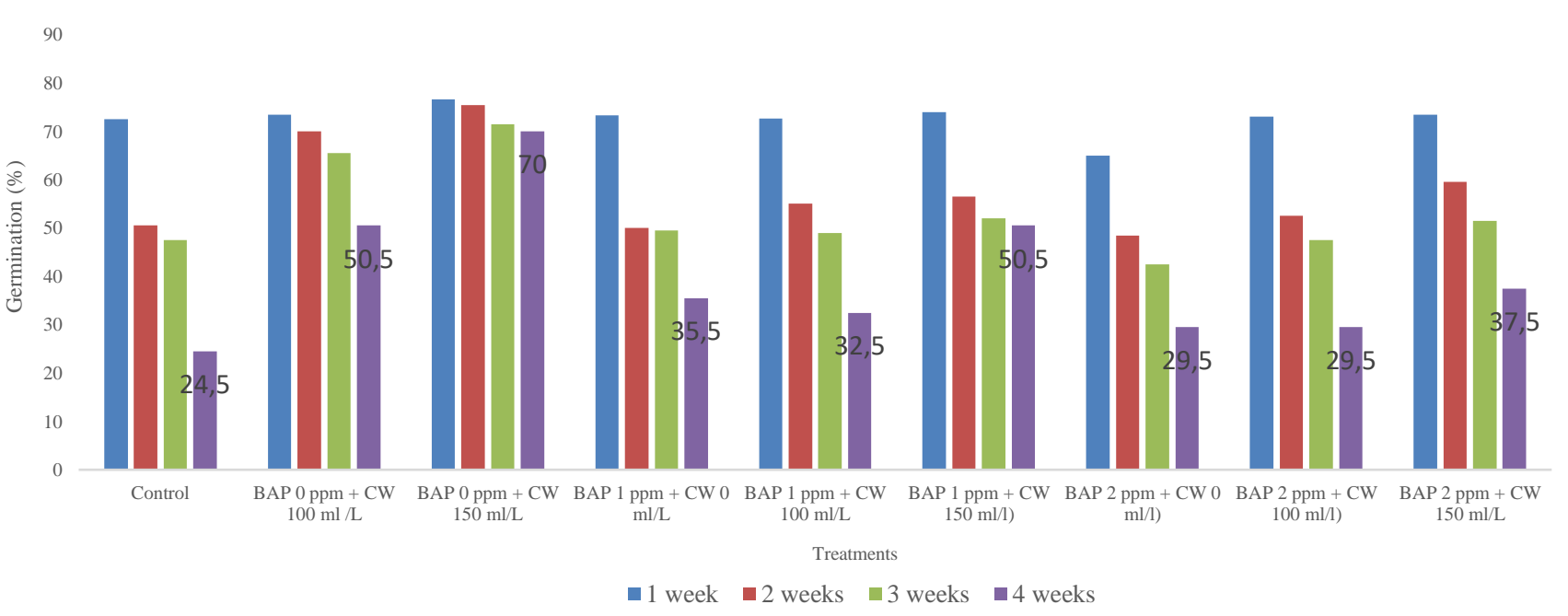

Fig. 2. Effects of plant growth regulators on the germination percentage of Chrysanthemum synthetic seeds on each treatment medium after 1, 2, 3 and 4 week storage period

The treatment of encapsulation media that still retains germination power is obtained in BAP 0 ppm + Coconut Water $150 \mathrm{ml} / \mathrm{L}$, which has the best germination percentage which is more than $70 \%$ at storage period of 1 week, 2 weeks, 3 weeks, and 4 weeks that is, the percentage of germination is $76.7 \%$, $75.5 \%, 71.5 \%$ and $70 \%$. Thus, the treatment of the media that can maintain the best germination percentage value with the acquisition of more than $70 \%$ is in the BAP 0 ppm + Coconut Water $150 \mathrm{ml} / \mathrm{L}$.

As mentioned by [20] Synthetic seeds could be a good tool to propagate these types of plants and to store their propagules for a reasonable period of time.

The result of [22] in their Salvia synthetic seed research, conclude that shoot tips maintained their viability and ability to develop shoots even after 24 weeks of storage when they were encapsulated in $3 \%$ alginate with $1 / 3 \mathrm{MS}$ medium, sucrose $(1.5 \%)$ and GA3 $(0.25 \mathrm{mg} / \mathrm{l})$. It seems that cold stored synthetic seeds were superior in terms of their regrowth capacity than that of room stored ones for all the growth parameters studied. A promising degree of interaction was observed between $4^{\circ} \mathrm{C}$ and 45 days of storage interval for regrowth percentage as well as for shoot and root development [23]. However, the potential of cold and room stored synthetic seeds to convert into complete plants indicated that trimming and encapsulation had no negative effect on their regrowth and they still maintained meristematic characteristics.
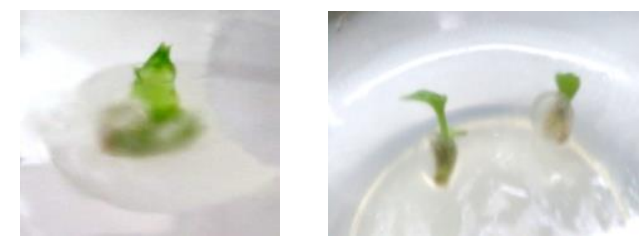

Fig. 3. Conversation of encapsulated seed into plantlets
According to the results showed at Table 1, there was no significantly different between the treatments, except on 1 week storage period. The culture medium containing coconut water $150 \mathrm{ml} / \mathrm{L}$ without BAP, with an average of 6.3 days, was found to be more effective in the storage of synthetic seed. In previous studies, no report was found stating that IBA increases the formation of leaves in plants. However, it is known that stimulating shoot formation and inhibiting of leaves are among the physiological effects of plant growth regulators of the cytokinin group [24]. Germination efficiency of synthetic seeds was decreased to $14 \%$ after 4 weeks of storage followed by rapid decrease in survival rate to $40 \%$ after 4 weeks. It was similarly with [25] on their cucumber synthetic seed research.

\section{CONCLUSION}

It can be concluded that this study was successful in developing a method of encapsulating shoot tip and nodal segments of Chrysanthemum. Synthetic seeds were formed using 4\% sodium alginate in MS salt solution as the gel matrix and $2 \%$ calcium chloride $(\mathrm{CaCl} 2 \cdot \mathrm{H} 2 \mathrm{O})$ for complexion. Encapsulated seeds had a higher germination percentage in MS salt solution supplemented with $150 \mathrm{ml} / \mathrm{L}$ coconut water as matrix gel. The viability of synthetic seeds were decrease on 4 weeks storage period, compared to the 1, 2 and 3 weeks storage period

\section{ACKNOWLEDMENT}

We express our gratitude to the Directorate of Research and Community Service (DRPM), Ministry of Research, Technology and Education of Indonesia, for the provision of PUPT scheme research grants in the year 2017. 


\section{REFERENCES}

[1] H. Ara, U. Jaiswal, and V.S. Jaiswal, "Synthetic Seed: Prospects and Limitations," Curr. Sci., vol. 78, pp. 1438-1444, 2000.

[2] P. Nongdam, "Development of Synthetic Seed Technology in Plants and Its Applications: A Review,” Int. J. Curr. Sci., vol. 19, pp. 86-101, 2016.

[3] S. Gantait and S. Kundu, "Artificial Seed Technology for Storage and Exchange of Plant Genetic Resources" in Advanced Technologies for Crop Improvement and Agricultural Productivity, C.P. Mali, Eds, Jodhpur: Agrobios (International), 2017.

[4] A.S.H. Nesreen, "The Green Revolution via Synthetic (Artificial) Seeds: A Review,” Res. J. Agric. Biol. Sci., vol. 7, pp. 464-477, 2011.

[5] M. Kikowska and B.Thiem, "Alginate-Encapsulated Shoot Tips and Nodal Segments in Micropropagation of Medicinal Plants," Herba Polonika, vol. 57, pp. 45-57, 2011.

[6] N.A. Siddique, M. Mujeeb, M. Rashid, and K. Hussain, "Synthetic Seed Production: Its Relevance and Future Panorama," Am. J. Pharmtech Res., vol. 3, pp. 382-397, 2013.

[7] D. Ravi and P. Anand, "Production and Applications of Artificial Seeds: A Review," Int. Res. J. Biological Sci., vol. 1, pp. 74-78, 2012.

[8] H.F. Sakhanokho, C.T. Pounders, and E.K. Blythe, "Alginate Encapsulation of Begonia Microshoots for Short-Term Storage and Distribution," Sci. World J., vol. 2013, pp. 1-7, 2013.

[9] A.M. Badr-Elden, "An Effective Protocol For In Vitro Storage and Ex Vitro Re-Growth of Strawberry Capsules," Atlas J. Chem. Biochemistry, vol. 1, pp. 30-38, 2013.

[10] I. Pinker and A.S.S.A. Abdel-Rahman, "Artificial Seeds for Propagation of Dendranthema X grandiflora (Ramat.)," Propag. Ornam. Plants, vol. 5, pp. 186-191, 2005.

[11] R.M. Taha, N. Mahmad, J.S. Yaacob, N. Abdullah, and S. Mohajer, "Synthetic Seeds Production and Regeneration of Oxalis triangularis For Mass Propagation and Conservation," International Journal of Environmental Science and Development, vol. 4, pp. 461-464, 2013.

[12] N.A. Siddique, M. Mujeeb, M. Rashid, and K. Hussain, "Synthetic Seed Production; Its Relevance and Future Panorama," Am. J. Pharmtech Res., vol. 3, pp. 382-397, 2013.
[13] N. Panwar, “Artificial Seed: A Practical Innovation,” Res. Rev.: J. Agric. Allied Sci., vol. 4, pp. 1-4, 2015.

[14] Warnita and I. Suliansyah. Effect of Alginateon Microshoot Encapsulation of Potato (Solanum tuberosum L.),' Jerami, vol. 1, pp. 139-143, 2008.

[15] I. Roostika, R. Purnamaningsih, Y. Supriati, I. Mariska, N. Khumaida, and G.A. Wattimena, "Artificial Seed Formation of Pineapple," vol. 22, pp. 316-326, 2012.

[16] Iffah, P. Dewanti, and S. Hartatik, "Growth of Sugarcane Synthetic Seed by Application of Sodium Alginate through Somatic Embryogenesis,” Berk. Ilm. Pertan., vol. 1, pp. 1-4, 2015.

[17] Sumaryono and R.T. Saptari, "Effect of capsule matrix on germination of synthetic seeds of tea (Camellia sinensis L.)," Menara Perkeb., vol. 83, pp. 54-59, 2015.

[18] C.E.S. Himayani and W. Muslihatin, "Produksi Benih Sintetik Tanaman Moringa oleifera,” J. Sains Seni, vol. 6, pp. 52-55, 2017.

[19] A. Standardi, "Encapsulation: Promising Technology for Nurseries and Plant Tissue Laboratories,” Agrolife Sci. J., vol. 1, pp. 48-54, 2012.

[20] H.Z. Rihan, F. Kareem, M.E. Mahrouk, and M.P. Fuller, “Artificial Seeds (Principle, Aspects and Applications)," Agron., vol. 7, pp. 1-15, 2017.

[21] I. Grzegorczyk and H. Wysokińska, "A Protocol for Synthetic Seeds From Salvia officinalis L.Shoot Tips,” Acta Biol. Cracoviensia Ser. Botan., vol. 53, pp. 80-85, 2011.

[22] K. Redenbaugh, Introduction. In: Redenbaugh K. (Ed.), Synseeds: Applications of Synthetic Seeds to Crop Improvement, California: Crc Press Inc., 1993..

[23] M. Ikhlaq, I.A. Hafiz, M. Micheli, T. Ahmad, N.A. Abbasi, and A. Standardi, "In Vitro Storage of Synthetic Seeds: Effect of Different Storage Conditions and Intervals on Their Conversion Ability," Afr. J. Biotechnol., vol. 9, pp. 5712-5721, 2010.

[24] E. Bektaş and A. Sökmen, "In Vitro Seed Germination, Plantlet Growth, Tuberization, and Synthetic Seed Production of Serapias vomeracea (Burm.F.) Briq.," Turk. J. Botan., vol. 40, pp. 584-594, 2016.

[25] B. Tabassum, I.H. Nasir, A.M. Farooq, Z. Rehman, Z. Latif, and T. Husnain, "Viability Assessment of In Vitro Produced Synthetic Seeds of Cucumber,” Afr. J. Biotechnol., vol. 9, pp. 7026-7032, 2010. 